\title{
FAST FERRITE TUNER FOR THE BNL SYNCHROTRON LIGHT SOURCE*
}

\author{
E. Pivit ${ }^{1}$, S.M. Hanna, and J. Keane \\ National Synchrotron Light Source \\ Brookhaven National Iaboratory \\ Upton, New York
}

$$
\text { BNL }-46182
$$

DE91 013533

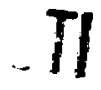

\begin{abstract}
A new type of ferrite tuner bas been lested at the BNL. The ferrite tuner uses garnet siabs partially filliri $g$ a stripline. One of the important features of the tuner is that the ferrite is perpendicularly biased for operation above FMR, thus reducing the magaetic losses. A unique desiga was adopted to achieve efficient cooling. The principle of operation of the tuner as well as our preliminary results on tuning a $52 \mathrm{MHz}$ cavity are reported. Optimized conditions under which we demonstrated linear tunability of $80 \mathrm{KHz}$ are described. The tuner's losses and its effect on higher-order modes in the cavity are discussed.
\end{abstract}

\section{INTRODUCTION}

Tuning of RF cavities in storge rings is needed to maintain accelerating gap voltage under varying beam load conditions. Conventionally, this has been done using motordriven capacitive posts or inductive loops. Under conditions of fast injection, the need exists for a different type of uner in which the mechanical movernents of the tuming elements are eliminated. In this paper we report on a Fast Ferrite Tuner (FFT) to be used in the VUV storge ring at the National Synchrotron Light Source.

At the NSLS, the VUV-ring is an electron stornge ring dedicated to syachrotron radiation in the UV rage and is normally operated at $745 \mathrm{MeV}$. A single $52 \mathrm{MHz}$ accelerating eavity is used to compenasate for the $14.7 \mathrm{KW}$ of synchrotron radintion per ampere of stored beam. This RF cavity requires denuning range of $50 \mathrm{KHz}$ to maintain the correct phase relation between the cavity voluge and the beam curreat. Curreatly, a combination of a mechanically driven loop tuner and water temperature variation is used to provide the required denuning. Our objestive is to replace these techniques by the ferrite tuner, thus eliminating the beam instabilities associated with cerain positions of the mecbanical tweer.

Work performed under the auspices of the U.S. Deparment of Energy.

'ANT Nachrichtechnik, GmbH, W. Germany.

\section{PRINCIPAL OF OPERATION}

$$
\text { JUN } 141991
$$

\section{A. Basic Concept:}

A loop-coupled transmission line is used to ture the 52 MHz cavity. The transmission line is partially loaded by ferrite. By changing the bias field, the permeability of the ferrite can be changed. This results in the change in the circulating current in the coupling loop, which in turn changes the magnetic field in the region around the loop. Thus, the ratio of the magnetic to electric stored energy in the cavity is changed with the accompanying change in the cavity's resonant frequency.

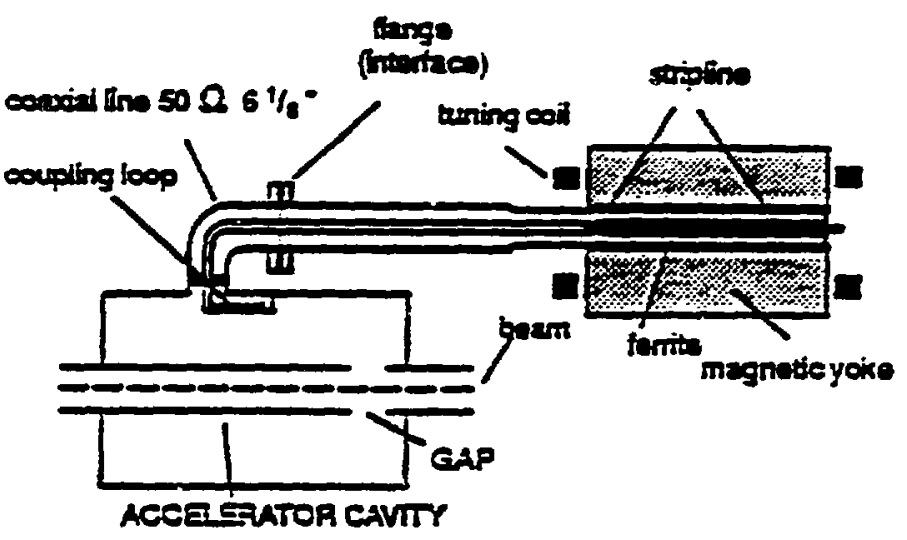

Fig. 1. Configuration for the ferrite tuner and the RF cavity.

\section{B. Material:}

Recently, the use of substituted yttrium iron garnet (MG) has been suggested $[1,2]$. The choice of such micrownve ferrite enjoys the important advantage of custom tailoring the saturation magnetizntion to the specific application and thus minimizing the bias field requirement. The permeability changes 25:

$$
\mu=1+\frac{4 \pi M_{1}}{H}
$$

where $4 \pi \mathrm{M}$, is the sanuration magnetization, and $\mathrm{H}$ is the de field inside the ferrite.

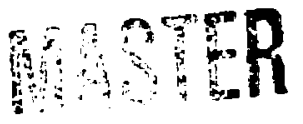




\section{DISCLAIMER}

This report was prepared as an account of work sponsored by an agency of the United States Government. Neither the United States Government nor any agency thereof, nor any of their employees, makes any warraniy, express or implied, or assumes any legal liability or responsibility for the accuracy, completeness, or usefulness of any information, apparatus, product, or process disclosed, or represents that its use would not infringe privately owned rights. Reference herein to any specific commercial product, process, or service by trade name, trademark, manufacturer, or otherwise does not necessarily constitute or imply its endorsement, recommendation, or favoring by the United States Government or any agency thereof. The views and opinions of authors expressed herein do not necessarily state or refiect those of the United States Government or any agency thereof. 
The garaet is biased above sanration and with the de magnecic field perpendicular to the if mengetic field. The ferrite is operated above the gyromagnetic resonunce in the region where the discipative part of the permeability, $\mu^{*}$ is low, thus reducing the magnetic losses.

\section{Circuit Model:}

The ferrice runer can be modeled as a short-circuited trasmission line whose effective leagth varies as a function of the bias current, $l(I)$ as shown in Fig. 2.

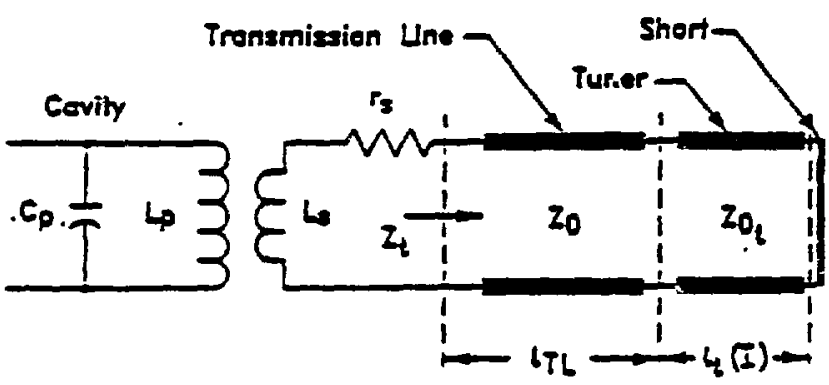

Fig. 2. Transmission line model for the ferrite tuner.

From the tunet equivaleot circuit shown in Fig. 3 (2), one can deduce the coupled impedence reflected into the cavity. This is shown in Fig. 3(b).

$$
Z_{e}=\frac{(\omega)^{2}}{Z_{s}+Z_{s}}=\frac{\Sigma_{s} I_{\mu}\left(\omega L_{1}\right)\left(\omega L_{L}\right)}{Z_{s}+Z_{b}}
$$

Since the resistive part of $Z_{2}$ is regligible, then $Z_{1}=j \omega L$.

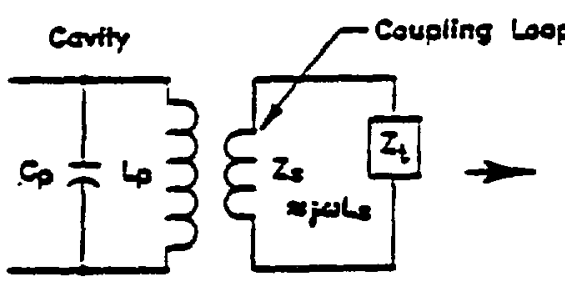

(a)

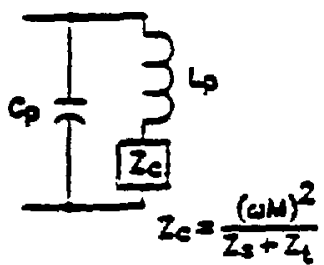

(b)
Fig. 3. Equivalent circuits for the tuner and coupling structure.

If we define $K^{2}=K_{p} K_{n}$, we obtain

$$
Z_{s}=\frac{\Gamma^{2}\left(\omega L_{j}\right)\left(\omega L_{p}\right)}{Z_{s}+Z_{s}}=\frac{-\Sigma^{2} Z_{p} Z_{s}}{Z_{s}+Z_{t}}
$$

The resonaoce frequeacy of the cavity is

$$
2 \pi f=\frac{1}{\sqrt{L_{\alpha} C}} \text { where } \quad L=L,\left\{1-\frac{X^{2}}{1-\frac{Z_{f}}{Z_{s}}}\right]
$$

If the capacitance is fixed, then we have

$$
\frac{\Delta f}{f}=-\frac{1}{2} \frac{\Delta L_{q}}{L_{f}}
$$

Maximum change in the cavity frequency will be between open circuit $\left(L_{-1}=L_{\gamma}\right)$ and short circuit $\left(L_{e f}=L_{1}[1-K\rangle\right)$. Thus the maximum amount of frequency shift is limited by the degree of coupling, $K:$. Our experimental results showed clearly this effect.

\section{RESULTS OF PRELIMINARY TUNER TESTING}

\section{A. Tunability:}

We bave optimized the coupling between the turer and the cavity as well as the leogtb of the connecting transmission line to obtain the required tumability. A length of $\ell=56.5^{\circ}$ gave 2 linear tuning cbaracteristics 25 sbown in Fig.4. The cavity's frequency is plotted against the turer biasing current, I The maximum frequency shift obcained is $78 \mathrm{KHz}$, which exceeds the design goal of $50 \mathrm{KHz}$. The voluge standing-wave zatio (VSWR) at the exvity's driviog port varied between VSWR $=1.064 \mathrm{a} I=0 \mathrm{~A}$ and $\mathrm{VSWR}=1.414 \mathrm{at} I=130 \mathrm{~A}$.

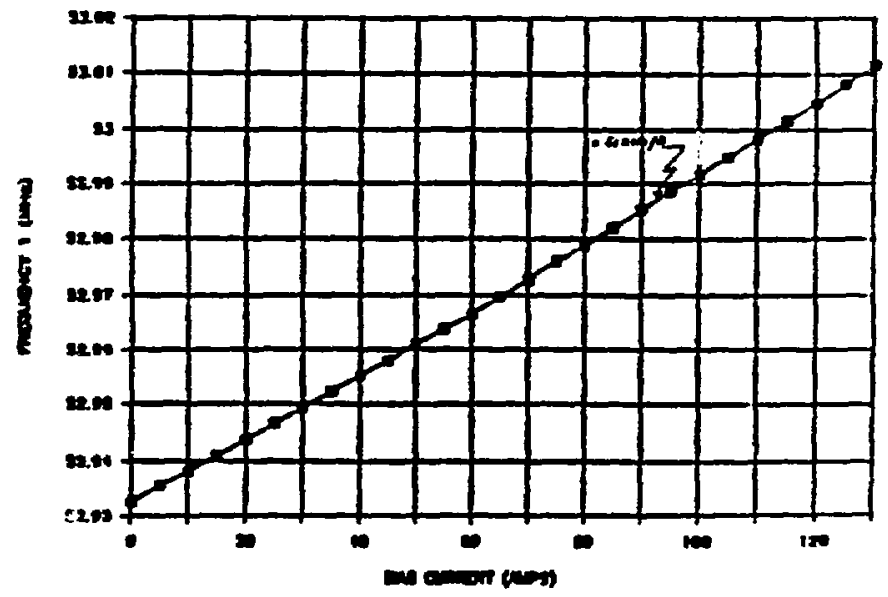

Fig. 4. Tuning characteristics of the FFT.

\section{B. Variation of Tuner Losses:}

The $Q$ of the tuner system was measured as a function of the bias current. The results of the measuremeat are shown 10 Fig. 5. It can be seen from the figure that $Q$ first increases with bias current up to 30 amperes and then decreases. Since we are biasing the ferrite above FMR. then, as we increase the bias field: $\mu^{\circ}$ becomes smaller resulting in lower magneth 
loss in the ferrite and subsequently higher $Q$. As for tho slight decrease in $Q$ for higher bies currents, wo bave considered different effects. One possibio explaination would be the fact that the runer effecively becomes a shorter trasmission line as we increase the bias. Thus, for a given voltnge at the coupling loop, the electric field it the ferrite increases. This results in the observed increase in losses as manifested by the monotonic decrease in $\mathbf{Q}$.

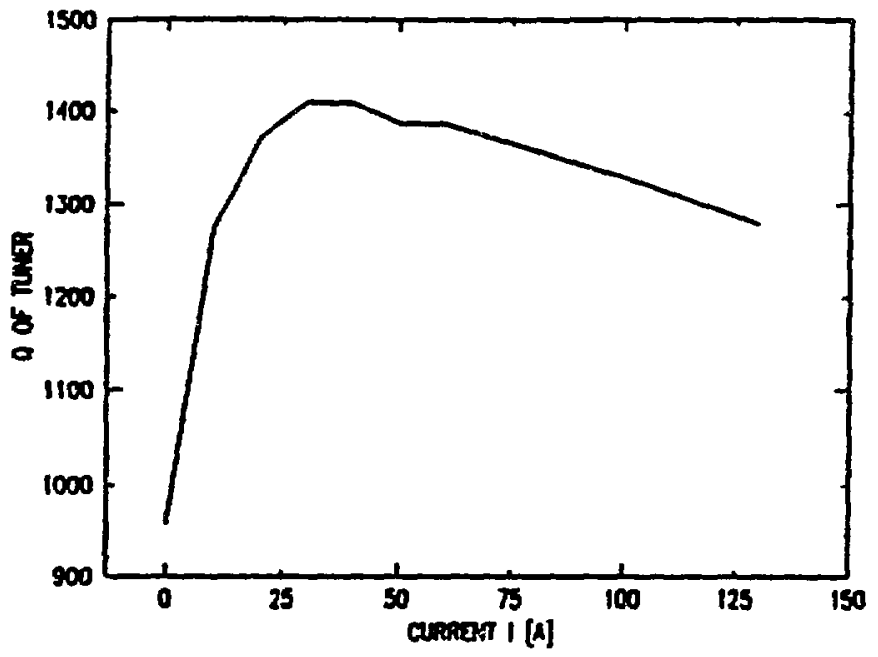

Fig. 5. Variation of the $Q$ of the muer system.

\section{Effect of Tuner on the Cavity's Higher-Onder Modes:}

To investigate the effect of the suner on the exciution of higher-order modes (HOM's) in the VUV-ring cavity, we have analyzed the HOM's induced by the tuner in a replicate study cavity. Specifically, we probed these modes that resulted in a change of field in the accelerating gap. Detriled results of these gap mensurements will be reported in a separate publication. Up to $200 \mathrm{MHz}$ there was no observed change in the cavity's response 23 shown by comparing Fig. 6 ( $a$ and $b$ ) to Fig. 7 ( $a$ and $b$ ).

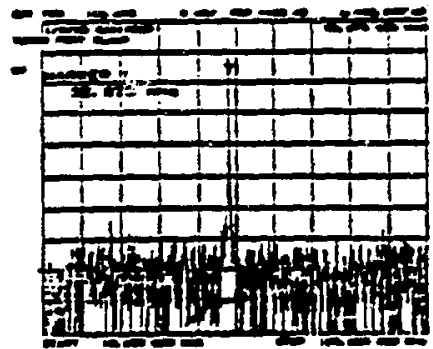

(a)

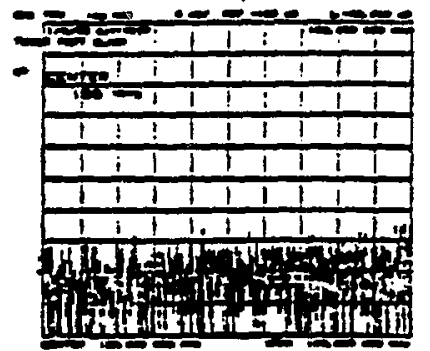

(b)
Fig. 6. Cavity response with the runer port blocked.

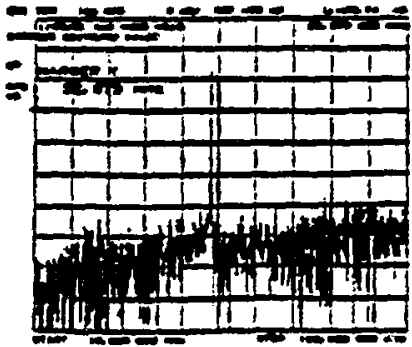

(a)

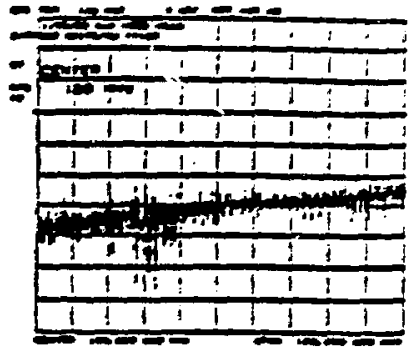

(b)
Fig. 7. Cavity response with the tuner coupled to the cavity $(I=130 \mathrm{~A})$.

At higher frequeacies, the tuner shifted some of the cavity's HOM's and introduced additional ones. We show in Fig. 8 (a and b) the mode at $272 \mathrm{MHz}$ as an example. Curreatly, we are studying differeat approsches to suppress the additional HOM's that are due to the ferrite tuner. This includes the use of a terminated waveguide as a suppressor.

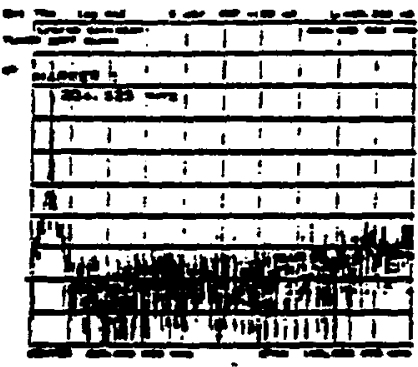

(a)

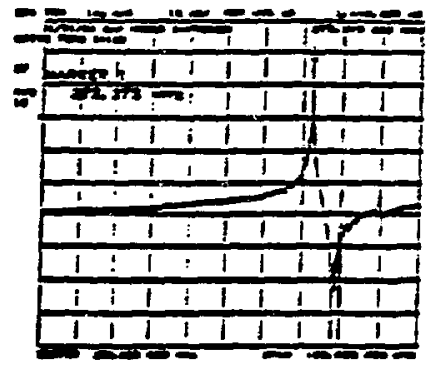

(b)
Fig. 8. Shift in one of the cavity's HOM's due to tuner:
(a) tuner port blocked.
(b) $I=130 \mathrm{~A}$

\section{CONCLUSTONS}

From our preliminary tests on the wew ferrite turner, it is clear that we were able to achieve the design goals concerning the tumbility required. The low moer losses, as demonstrated by the measured bigh tuner's $Q$, are credited to the normal bias approach which we use and biasing the ferrite above FMR. The design approach adopted also has the advantage of efficient cooling of the garaet shabs in the stripline configuration.

\section{ACKNOMLEDGENENT}

We wish to scknowledge the technical support of R.D'Alase and W. Broome.

\section{REEERENCES}

[1] W. R. Smythe and T. G. Brophy, IEEE Trans. on Nuel. Sci.. NS.32. No.5,2951 (1985).

[2] R.M. Hutcheon. Proc. of the IEEE Part. Aceel. Conf., 1543 (1987). 